\title{
The Effect of Sibship Size on Educational Attainment in China: Period Variations
}

\author{
Yao Lu and Donald J. Treiman
}

(Final version published in American Sociological Review)

Lu, Yao and Donald J. Treiman. 2008. "The Effect of Family Size on Educational Attainment in China: Period Variations.” American Sociological Review 73(5):813-834.

Contact information

Yao Lu

Department of Sociology, Columbia University

501 Knox Hall

New York, NY 10027, USA

Phone: 212-854-5442

Email: yao.lu@columbia.edu

\section{Acknowledgements}

This research was inspired by a presentation Vida Maralani gave on family size and educational attainment in Indonesia at a seminar of the California Center for Population Research in Spring 2004 (see Maralani 2004). Earlier versions of this article were presented at a meeting of the ISA Research Committee on Social Stratification and Mobility, Rio de Janeiro, August 2004, and at the 2005 Annual Meeting of the Population Association of America. We thank the discussants of these presentations: Richard Arum, Emily Hannum, and Parfait M. Eloundou-Enyegue; the editors; and four anonymous reviewers. Data collection was supported by grants to UCLA from the National Science Foundation (SBR-9423453), the Luce Foundation, the Ford FoundationBeijing, and the University of California Pacific Rim Program. 


\begin{abstract}
In industrialized nations, sibship size generally depresses educational attainment: the larger the number of siblings, the lower the educational attainment. This association is much less consistent in developing nations, however. This article examines the effect that the number of siblings has on educational attainment in China, a nation that has experienced sharp vacillations between policies designed to promote equality (between urban and rural residents and between men and women) and policies designed to promote economic development. The implementation of these policies in the educational arena has alternately reduced and increased competition for educational resources and, as we show, has correspondingly reduced and increased the effect of sibship size on educational attainment.
\end{abstract}




\section{INTRODUCTION}

Studies conducted in the United States and Western industrialized societies show a clear negative effect of sibship size on children's educational attainment, even when controlling for family socioeconomic background (Blake 1981, 1989; Blau and Duncan 1967; Downey 1995; Featherman and Hauser 1978; Mare and Chen 1986). Each additional sibling reduces schooling by as much as one-fifth of a year (Featherman and Hauser 1978; Mare and Chen 1986). This is a strong effect, exceeding that of many other family origin variables (Blake 1989).

The inverse relationship between sibship size and educational attainment often is explained by a "resource-dilution" hypothesis, which posits that finite parental resources are distributed among siblings and each additional sibling thus reduces the family resources available to each child (Anastasi 1956; Blake 1981; Downey 1995). Increasingly, however, evidence shows that the negative effect from the number of siblings is neither universal nor inevitable, particularly in developing countries. Rather, it is contingent on demographic, socioeconomic, and political factors external to the family that influence both the availability of resources and their internal allocation within a family.

China provides a particularly interesting case, as the past 60 years have seen remarkable social, economic, and political changes. China has experienced dramatic socioeconomic development, especially since 1978; state educational policies have vacillated between an emphasis on educational equality and an emphasis on expertise; and, beginning in the 1970s, there has been a concerted state intervention with respect to fertility control. All these changes may influence how the number of siblings affects educational attainment, for reasons discussed in greater detail below. Moreover, gender and place, two important aspects of stratification in China, may interact with sibship size in influencing educational outcomes as a result of persistent son preference and rural-urban disparities.

Using data from the study Life Histories and Social Change in Contemporary China, a national probability sample of Chinese adults surveyed in 1996, we investigate the association between sibship size and educational attainment in China over four historical periods characterized by differing socioeconomic conditions and educational and other state policies. We also study the mediating effect of gender and place on this association.

\section{SIBSHIP SIZE AND EDUCATIONAL ATTAINMENT}

The effect of sibship size on educational attainment has been studied for the past two decades. Initially, a no-effect hypothesis prevailed. The seeming effect from the number of siblings was thought to be a spurious artifact of extraneous factors, particularly the fact that socioeconomically disadvantaged families tend to have more children. Studies conducted in the United States and other Western societies, however, demonstrate a clear negative effect of sibship size on children's educational attainment (school enrollment, standardized test performance, and completed education) net of family socioeconomic status (Powell, Werum, and Steelman 2004; Steelman et al. 2002). 
The prevailing explanation for the sibset size effect is the "resource-dilution" hypothesis (Anastasi 1956; Blake 1981; Downey 1995). Resources include nonmaterial assets such as parental time, attention, and emotional support, as well as material assets such as financial investments in children's education and study environments. As sibship size increases, these resources are distributed more thinly over each child. In a study that explicitly tested the resource-dilution theory, Downey (1995) found strong support for the hypothesis that parental resources account for the inverse relationship between sibship size and educational outcomes. $\mathrm{He}$ also found that material resources decreased more rapidly with sibship size than did nonmaterial resources.

Many studies in psychology have established links between sibship size and children's cognitive development, even when controlling for the effects of maternal IQ and family socioeconomic status (Anastasi 1956; Belmont and Marolla 1973; Breland 1974; Gottfried and Gottfried 1984; Nisbet and Entwistle 1967). Marjoribanks, Walberg, and Bargen (1975) theorized that a child's intellectual ability depends crucially on the amount of nonmaterial resources available, such as parental attention (see also Bakeman and Brown 1980; Clarke-Stewart 1988). The amount of parental attention available to a given child depends, though, on the number of children in the family. Children with more siblings are penalized due to the limited attention they receive in terms of the quantity, and possibly the quality, of parent-child interactions, which results in a slower rate of early development.

\section{THE EFFECT OF SIBSHIP SIZE IN DEVELOPING NATIONS}

As noted, a negative effect of sibship size has been widely observed in Western societies (albeit with diminishing force in recent periods [Downey 1995; Powell et al. 2004]), and sibship size has become a standard variable in studies of educational attainment. Emerging evidence, however, especially in the developing world, indicates that the negative association is not universal and often varies across contexts and population subgroups (Gomes 1984; Lloyd 1994; Lu 2005; Maralani 2004; Shavit and Pierce 1991). This suggests the need to study conditions and institutions external to the family that influence within-family resource availability and distribution (Buchmann and Hannum 2001). Although a number of factors mediate the effect of sibship size, we focus on those we can study: policy interventions and differentials by gender and place.

The extent to which sibship size matters at the micro level may depend on specific public policy contexts at the macro level (see Powell et al. 2004 for a good review). For example, government subsidies may reduce the direct costs of schooling, thus weakening the importance of material resources and the negative effect of sibship size on education (Behrman, Pollak, and Taubman 1989; Park 2005; Pong 1997; Post and Pong 1998; Sudha 1997; Xu 2003). Behrman and colleagues (1989) found a negative relationship between sibship size and years of schooling in the United States, except in special situations that equalized access to financial resources to pay for education, such as the G.I. Bill and loan programs operating in the late 1980s. Similarly, Post and Pong (1998) found a diminishing sibship size effect on school attainment in Hong Kong during the late 1970s, corresponding to a major expansion in free schooling. Such benefits, though, may be differentially available to different population subsectors. For example, in Malaysia most state subsidies are reserved for ethnic Malays. This affirmative action policy 
neutralizes the detrimental impact of sibship size on school enrollment among Malays. In contrast, a clear negative relationship is observed among Chinese and Indians, for whom state subsidies are scarce (Pong 1997; Sudha 1997). In summary, if a state subsidizes children's education, parental resources matter less, as does sibship size.

Gender and place may also mediate the effect of sibship size. In societies with strong sonpreference norms, such as China and most other East Asian countries, parents may choose to invest in the education of sons rather than daughters when their resources are inadequate to do both (Parish and Willis 1993). The effect of sibship size on the education of females should thus be stronger than the effect for males, at least when parental resources are stretched thin (Lloyd 1994; Sudha 1997). A recent study in Taiwan lends support to this claim by showing a stronger sibship size effect for girls (Chu, Xie, and Yu 2007). A similar argument would lead us to expect a greater impact of sibship size on educational attainment in rural areas, at least in nations like China, where rural families are poorer and educational subsidies are more limited than in urban areas.

\section{EDUCATIONAL POLICIES AND EDUCATIONAL STRATIFICATION IN CONTEMPORARY CHINA}

Since 1949, the Chinese government has pursued the twin goals of economic development and social equality. Given the limited resources of the new government, however, these two goals were substantially incompatible (Hannum and Xie 1994). Although China experienced strong educational expansion throughout the twentieth century, both before and after the communist government took power (Deng and Treiman 1997), since the beginning of the communist era there has been great tension between the two goals. The result has been periodic shifts in educational policy between an ideological socialist egalitarian agenda and a practical competitive agenda ${ }^{1}$ (Hannum 1999; Hannum and Xie 1994; Tsang 2000). The socialist egalitarian agenda emphasized equal opportunities (mass education) and socialist ideals ("redness") under a uniform curriculum designed to promote social equality and reduce status differences. As shown by numerous studies, specifically Hannum and Xie (1994), such policies dominated before 1978 and reached their apex during the 1966 to 1976 Cultural Revolution. In contrast, the practical competitive agenda focused on education for economic efficiency (expertise) and emphasized personal advancement as a device for producing experts who could promote economic development. An important goal of this strategy was to maximize economic returns on governmental investments in education. This agenda was ascendant during Liu Shaoqi's dominance in the early 1960s and, most importantly, during the post-Mao economic reform era that began in 1978 .

In China, whether one lives in an urban or a rural area is crucial in determining one's economic and educational opportunities (Knight and Shi 1996; Wu and Treiman 2004, 2007). The ruralurban gap in educational attainment results from differences in the levels of public funding and the quality and availability of schools, differences in rural and urban families' ability to pay for schooling, and differences in the level of cultural capital possessed by each group (Treiman 2007). The Chinese state currently regards such disparities as a serious problem because of their negative implications for social equality. This urban-rural gap remained very large as of 1996. Although some recent initiatives have improved rural schools, they generally postdate our 1996 
survey and hence have no effect on the analysis. The egalitarian agenda placed great importance on eliminating the rural-urban gap, whereas the competitive agenda tended to favor the more developed urban areas (Hannum 1999).

Despite efforts by the government to raise women's status, there is still a persistent son preference in China (Bauer et al. 1992; Hannum and Xie 1994). Decisions about schooling reflect parents' perceptions of gender roles and their understanding of gender differences in labor market returns on education investments. Traditional Chinese marriage and kinship patterns are strongly patrilocal and patrilineal, with married women expected to care for their husbands' parents rather than their own. Parents therefore anticipate much greater old-age support from their sons than from their daughters, which means they have a much stronger incentive to educate their sons (Lavely et al. 1990). Such practices are still prevalent in rural China today, and the attendant norms persist even in the urban population (Yan 2003).

A second incentive comes from men's greater earning power relative to women and men's greater access to jobs requiring educational credentials (Summerfield 1994). Men's greater earning power, more or less universal across societies (Roos and Gatta 1999; Treiman and Roos 1983), means that it usually is more rational to maximize a son's earning power.

Similar to changing rural-urban differentials, gender differences in educational attainment reflect the vacillation of educational policies between egalitarianism and competitive growth. Periods with a strong emphasis on equality are characterized by decreased gender inequality in education, whereas periods focusing on economic development are characterized by increased gender inequality (Hannum and Xie 1994).

The vacillation of educational policies can be reasonably well captured by distinguishing four periods in recent Chinese history. We posit sharply different educational stratification regimes, specifically differences in the effect of sibship size on educational attainment, across the four periods. Although finer distinctions would be preferable, our sample size is not large enough to sustain analysis of more than four periods.

\section{Period 1: Precommunist Era (Before 1950)}

Before the 1949 transition to communism, China's economy suffered from nearly two decades of war (the Anti-Japanese War and the Civil War). The economy collapsed and the level of socioeconomic development was extremely low. The formal educational system, never very extensive, was badly disrupted, resulting in extremely limited educational opportunities. Government policies put little emphasis on either elite or mass education. As a result, over 80 percent of the urban population and nearly 95 percent of the rural population were functionally illiterate (Ministry of Education 1981).

\section{Period 2: The Early Years After the Transition to Communism (1950 to 1965)}

China has undergone numerous changes since the establishment of the communist regime. The period from 1950 (when the new government firmly established control) to 1958 was a time of economic recovery, during which the primary goal was to promote rapid economic development 
(Zhou, Moen, and Tuma 1998). Because of the increasing demand for skilled labor needed for national economic development, educational opportunities expanded. The educational policies during this period emphasized both economic development and social equality (Hannum and Xie 1994). Besides building a national education system, efforts focused on the early years of schooling, with an emphasis on establishing universal primary education and reducing illiteracy (Tsang 2000). However, with scarce societal resources and an emphasis on economic development, education did not in fact expand to a degree that significantly reduced inequality.

In response to Mao's idea of accelerating the movement toward true communism, the Great Leap Forward period from 1958 to 1960 promoted educational equality through a substantial expansion of access to education, especially for peasant and working-class children (Tsang 2000). At the same time, the attempt to promote rapid economic development failed, which led to an economic collapse and a nationwide Great Famine (Hannum and Xie 1994). As a result, although education became more available, many parents kept their children out of school to assist with economic support and to reduce family expenses. This was especially true of rural families, who suffered the brunt of the economic collapse, and also for girls because traditional son preferences made girls more vulnerable to economic hardship of any kind (Hannum and Xie 1994). In short, during the Great Leap Forward and its aftermath, educational policies promoting equality were greatly undermined by the economic collapse and the Great Famine.

After three years of sharp economic decline (1958 to 1960), Liu and Deng took control of national affairs in 1961 and, among other things, revamped educational policies (Tsang 2000). They believed that the limited resources should be spent where they would be most effective. To produce the technically-trained personnel needed for economic development, Liu and Deng introduced a competitive educational agenda and abruptly reversed the previous egalitarian policy, building on the high-quality urban school systems (academic elite schools), from which they could expect faster economic returns, and closing low-quality schools, especially in rural areas (Hannum 1999). Overall, despite expansion of the educational system relative to the precommunist period, educational inequalities remained strong from 1950 to 1965. This was especially true for rural residents and girls due to great economic constraints and the competitive educational agenda implemented for part of this period. ${ }^{2}$

\section{Period 3: Cultural Revolution (1966 to 1976)}

Dissatisfied with Liu and Deng's policies, Mao again seized control of the party in 1966. He returned to the earlier emphasis on ideological egalitarianism and collectivist production (Tsang 2000), launching the Great Proletarian Cultural Revolution. During the Cultural Revolution period, policies promoting educational equality and ideological purity ("redness") regained priority. Almost all secondary and tertiary educational institutions were closed during the early years of this period (secondary schools from 1966 to 1968 and tertiary institutions from 1966 to 1972). When they reopened, they concentrated on political indoctrination and instituted policies and practices designed to narrow the gaps between manual and nonmanual workers, urban and rural people, and workers and peasants (Hannum 1999). Politically-oriented admission criteria prevailed, often based on class backgrounds, which accomplished the goal of increasing the enrollment of worker and peasant children. There was also an ideological emphasis on gender equality during those years (Bauer et al. 1992). 
Because an essential goal of the Cultural Revolution was to reduce differences between the peasantry and the rest of the population (Deng and Treiman 1997), key-point (academic elite) schools, multiple tracks, vocational education, and entrance examinations all were abolished. At the same time, many new primary and especially secondary schools were opened in villages and made affordable, although typically with a low academic standard (Unger 1982). Consequently, the fraction of rural children attending middle school increased (Han 2001). Colleges were closed to high school graduates yet open to a limited number of students with less education but from suitable political and family backgrounds (Zhou et al. 1998). These state interventions aimed at explicitly reducing class differences rendered educational attainment during this period less dependent on social origins than was the case previously (Deng and Treiman 1997). Furthermore, the egalitarian political climate had an equalizing effect on educational disparities between men and women (Hannum and Xie 1994).

\section{Period 4: Post-Mao ECONOMic Reform (1977 to 1996)}

With the repudiation of the Cultural Revolution after Mao's death, Deng geared development of the educational system to the advancement of economic modernization and reemphasized a competitive merit-based educational agenda. The rapid expansion of education during the Cultural Revolution was blamed for the low quality of many schools and, as a remedy, schools judged to be low-quality were closed. Meanwhile, key-point and vocational schools proliferated. Moreover, after 1978 the foundation of education financing was changed from a centralized system with a narrow revenue base to a decentralized system with a more diversified revenue base (Tsang 1996, 2000; Tsui 1997). This exacerbated funding disparities, particularly between rural and urban schools. Decentralization also led to an increase in educational fees, which particularly affected children in poor rural areas that were least able to subsidize schools. Finally, with the introduction of the Household Responsibility System (HRS) (which allocated collective land to individual families, who were allowed to sell their after-tax agricultural surplus on the open market), parents were more likely to keep children out of school due to the increasing economic value of child labor (Summerfield 1994).

All these factors contributed to an increase in educational inequality and to the curtailment of access to education for rural children in particular (Hannum 1999). These factors also exacerbated differentials in families' willingness to invest in their male and female children (Summerfield 1994). During the reform period, female participation in schooling declined at all education levels and the gender gap increased (Rong and Shi 2001). Although there have been efforts to increase schooling (e.g., the 1986 introduction, but still incomplete implementation, of compulsory lower secondary school) and to improve the quality of schools (Tsang 2003), the overall consequence of the post-Mao reforms was increased inequality in educational opportunities (Rong and Shi 2001).

\section{HYPOTHESES}

In summary, political changes over the past half century appear to have altered both access to education and the direct cost of education and have thus affected the ability and incentives of families to keep their children in school. We therefore expect sharp differences in the impact of 
sibship size on educational attainment across the four periods, as well as differences in the effects of place and gender across these periods. We formalize these expectations in the following hypotheses.

Hypothesis 1: During the period emphasizing educational egalitarianism (Period 3, the Cultural Revolution), the effect of sibship size should be negligible. In contrast, during the periods characterized by a competitive agenda and educational inequality (Periods 2 and 4), the larger the number of siblings, the lower the level of education that should be attained, net of other factors (for Period 1, see Hypothesis 3).

As noted, during the Cultural Revolution both resource constraints on families and educational demands on children were greatly reduced relative to the previous and subsequent periods. We thus expect that family differences in material and cultural capital were less important during this period than in the preceding and following periods characterized by meritocratic policies. Hence, the dilution of these resources in families with many children was less consequential.

Hypothesis 2: During competitive periods, the effect of sibship size is especially detrimental for the educationally disadvantaged - girls and rural children — whereas during egalitarian periods, such disadvantages are greatly reduced.

Hypothesis 2.1: The sibship size effect varies by sex. It is weak for boys in all periods but stronger for girls in meritocratic periods.

Due to strong male preference norms (Poston 2002), families attempt to secure education for their sons even when they experience resource constraints. We thus expect the effect of sibship size to be relatively weak for boys in all periods, despite shifting policies. In contrast, because educating daughters is generally regarded as less important, girls' educational opportunities are the first to suffer when there are many children or when resources are limited relative to the cost of education, as in the meritocratic periods. We thus expect that in such periods the gender gap in resource allocation was exacerbated, meaning that sibship size had especially large consequences for girls' schooling.

Hypothesis 2.2: The sibship size effect depends on type of place of residence, but in a complex way that varies by period.

The fundamental claim here is the same as in Hypothesis 1. However, competition for schooling in rural and urban areas varies across periods in complex ways. In China, the most important factor influencing educational attainment is residence (and residence rights) in an urban versus a rural area (Wu and Treiman 2004). The rural-urban divide reflects great institutional, social, and economic differences, which in turn affect both educational opportunities and resources (Knight and Shi 1996).

In the early years of the communist regime, government provision was weak in rural areas, and rural families were poorer than urban families. Relative educational costs were thus much higher, resulting in a more pronounced level of competition for limited family resources. For this reason, we expect a strong effect of sibship size for rural families in Period 2. During this period, 
however, the government concentrated investment on existing high-quality urban school systems. We thus expect a reduced sibship size effect for urban children.

In contrast, during the Cultural Revolution (Period 3) the government gave high priority to education for peasant children and opened many schools in rural areas. In addition, admissions criteria were revised to favor students with peasant backgrounds (jiating chushen). Under this egalitarian ideology, rural parents were encouraged to educate all their children. We thus expect that the sibship size effect was reduced for these children. At the same time, urban children's educational opportunities were restricted. Many urban schools were shut down, and admissions criteria were set to discriminate against or completely exclude children from urban backgrounds. Many urban students were "sent down" to the countryside to work as peasants (Bernstein 1977; Unger 1982). The state policies that promoted rural education at the expense of urban education led to a larger sibship size effect for urban children than in the preceding period.

Hypothesis 2.3 describes our expectations regarding Period 4:

Hypothesis 2.3: During the economic reform period, state policies such as the introduction of fertility control policies and the Household Responsibility System (HRS) also modified the sibship size effect: fertility control policies led to an increase in the negative effect of sibship size, especially in urban areas, while the HRS produced a positive sibship size effect. We thus expect a negative effect in urban areas but, due to the offsetting impacts of several factors, little net effect in rural areas.

Birth control policies were implemented in China from the 1970s on. As a result, the number of large families decreased, especially in urban areas. Moreover, families with few children were subsidized, and families with many children were fined, exacerbating disparities in educational resources. For this reason, we expect that the sibship size effect increased during the reform period, especially for urban children.

In rural areas, fertility controls were not strongly enforced during this period and thus probably had little impact. However, the decentralization of educational financing, noted earlier, strongly affected rural areas, resulting in increased school fees, which would be expected to increase the sibsize effect. This effect was offset, though, by the introduction of the HRS. Although this system sometimes resulted in the removal of children from school to contribute to family enterprises, we conjecture that when a family had several children, the optimal strategy was to diversify risk by putting some children to work while keeping others in school to gain enough education to obtain secure nonagricultural jobs. This suggests the possibility of two offsetting mechanisms in the reform period: an increase in the direct costs of education, which should increase sibship size effects, and an increased likelihood that parents with several children will keep at least some in school, which should reduce sibship size effects.

Hypothesis 3: At extremely low levels of economic development (the precommunist period), there is no effect of sibship size on educational attainment. 
When educational opportunities are extremely limited, sibship size matters little because almost no one attains much education (Hermalin, Seltzer, and Lin 1982; Lloyd 1994; Mueller 1984; Sudha 1997). Before 1950, China was at an early stage of socioeconomic development. Educational opportunities and facilities were extremely limited. Because most jobs demanded muscle power rather than human capital, education was not particularly valued. Parents thus had little incentive to invest in their children's education, which meant that resource dilution was not an issue.

\section{A CAVEAT ON METHODOLOGICAL ISSUES}

Before turning to the analysis, we need to consider two potential methodological difficulties: the possibility that we have the causal order between sibship size and education wrong, and the possibility that the observed sibship size effect is spurious because it reflects other aspects of family composition, in particular, birth order effects.

\section{ENDOGENOUS QUALITY-QUANTITY TRADEOFF}

First, we consider the causal order, or endogeneity, problem. The relationship between sibship size and educational outcomes may arise in part from the fact that parents base their fertility decisions on calculations as to how many children they can afford given their educational aspirations for their children (often referred to as the quality-quantity tradeoff; Steelman et al. 2002). In this case, the observed effect of sibship size will be exaggerated relative to the true causal connection. The question is whether such reverse causality is important or only a minor problem.

We find the claim that endogeneity is a major and universal problem unpersuasive. Several studies adjust for potential endogeneity by using exogenous fertility events such as twin births and sibling sex composition, adopting an instrumental variable approach. Some find little or no effect of sibship size (Black, Devereux, and Salvanes 2005a; Rosenzweig and Wolpin 1980), while others find the effect to be real (Conley and Glauber 2006; Lu 2005; Maralani 2004). Guo and VanWey (1999) perform a longitudinal analysis via change models to test the possibility that the sibship size effect results from unmeasured factors correlated with both family size and intellectual development and find no sibship size effect on test scores. Although their analysis is very thoughtful, it turns on the selection of a small, distinctive subsample and thus cannot easily be generalized (for critiques of their study, see Downey et al. [1999], Philips [1999], and Steelman et al. [2002]). Using similar models, Baydar, Hyle, and Brooks-Gunn (1997) find that family size does have a deleterious effect on aspects of the family environment that shape intellectual development. Finally, Steelman and colleagues (2002) suggest the possibility that sibship size matters more for educational attainment, which requires material resources, than for intellectual performance.

Still, it would be desirable to assess the seriousness of endogeneity for our analysis had we the data to do so. Unfortunately, we do not. An over-time fixed-effects analysis is not possible because we have only a single cross-section. This leaves the possibility of an instrumental variables approach. Despite our best efforts, this approach proved to be unsuccessful due to the lack of suitable variables. In principle, the policy regime at the time a child was born could serve 
as an instrument for sibset size in the next period. Even under the best circumstances, this would be a "noisy" instrument because our sibset size variable is the number of siblings when the respondent was age 14 and hence is contaminated by temporal variations in child mortality rates. Still, we tried to identify variations in fertility policy regimes and constructed an instrumental variable differentiating periods that emphasized fertility control, encouraged fertility, and promoted neither. Because this instrument is not measured at the individual level, it has little variability and cannot reflect the differential behavior of parents exposed to the same policy regime. Not surprisingly, a formal statistical test shows that it is a weak instrument.

Considerable evidence suggests that such tradeoffs are not a major problem for our analysis. Two recent studies address this issue in developing nations using individual-level instruments (Lu [2005] on South Africa; Maralani [2004] on Indonesia) and find relatively robust effects of sibship size on education. As these authors suggest, the quality-quantity tradeoff is not a major issue in populations with a traditional view of childbearing, although it may be important in populations that have adopted a developed-Western-nation view of childbearing. Because children have long been valued in China as a source of labor and a resource for old age support, we think that quality-quantity calculations were relatively uncommon in Chinese families until the very recent emergence of an urban middle class. Only the youngest urban cohort is thus plausibly subject to a modern "Western" view of childbearing. As we will see, this possibility hardly accounts for our overall pattern of findings.

Finally, we can point to two kinds of evidence inconsistent with the claim that fertility is strongly responsive to the policy changes that, we argue, mediate the effect of sibset size. First, if a sibship size effect was present in competitive periods because of endogenous tradeoffs, we would expect lower fertility rates in these periods relative to egalitarian periods. To assess this possibility, we computed the mean number of siblings for each of the four birth cohorts. We shifted the cutting points eight years toward the beginning of the century to capture the years in which the respondents were conceived. We found no evidence that women reduced their fertility in competitive periods. The means for the four periods are, respectively, 3.0, 3.6, 3.6, and 2.8. Second, one could argue that highly educated women are most prone to quality-quantity tradeoffs. That is, because such women are more committed to producing "high quality" children and more sensitive to what this entails than are women with less education, they should be particularly likely to reduce their fertility during competitive periods, making the negative effect of mother's education on fertility particularly large. To test this claim, we need to control for differences in family resources because well-educated women are also likely to be materially better off, which tends to offset the negative effect of a mother's education. Since we have no measure for level of living during childhood, we used father's education and father's occupational status as proxies and predicted, via OLS, the number of siblings as a function of mother's education, father's education, and father's occupational status. There is no significant effect of mother's education during the first two periods, but there is a negative effect during the last two periods: the coefficients for mother's education in the four periods are, respectively, $.024,-.021,-.093$, and -.089 . This pattern, too, is inconsistent with the quality-quantity tradeoff hypothesis. In summary, as best we can tell given the limitations of our data, there is no evidence that sibship size is endogenous to educational attainment.

\section{Sibling Configuration as a Confounding EfFect}


While most studies of sibship size effects focus on between-family inequalities and assume that resources are evenly allocated within families, some studies stress within-family inequalities by examining the effects of birth order and gender composition. Most of these studies find these factors have very little or no effect net of sibship size (Hauser and Sewell 1985; Kessler 1991; Kuo and Hauser 1997; Steelman and Powell 1985; Steelman et al. 2002). Observed effects of such measures may thus largely reflect their association with sibship size: although an early place in the birth order may be advantageous, this may simply reflect the fact that, as a mathematical necessity, low-birth-order children disproportionately come from small families.

A few studies make the opposite claim - that observed effects of sibship size are spurious artifacts of the association between sibship size and birth order (Black et al. 2005a). A potential problem for studies of this kind is the multicolinearity between birth order and sibship size that results from including both measures in a single model (correlations of .7 are not uncommon). If both measures are influential, however, omitting one causes the model to be underspecified.

An alternative way to study the effects of both factors is to decompose the sibship size effect into birth order, birth spacing, and sex composition effects (Chu, Yu, and Tsay 2004; Post and Pong 1998). A recent study in South Africa (Lu 2005) using such decompositions finds that the inclusion of birth order components hardly alters the sibship size effect, and birth order itself has no clear influence on schooling.

Unfortunately, our data do not permit such strategies because we have no information on birth order. This is not a major limitation because most of the evidence shows that sibship size effects are much more robust than other sibling configuration effects (Powell et al. 2004). Moreover, sibship size effects, which reflect between-family inequalities in educational chances, are much more sensitive to policy changes than are other sibling configuration effects, which reveal within-family inequalities. Since the focus of our analysis is the impact of policy on educational opportunities, we do not regard our inability to study, or to control for, sibling configurations as particularly troublesome.

\section{DATA, VARIABLES, AND METHODS}

\section{DATA AND Methods}

We use data from the survey Life Histories and Social Change in Contemporary China (Treiman and Walder 1996), a multistage stratified national probability sample of 6,090 adults ages 20 to 69 (Treiman 1998). Because the urban and rural populations were sampled at different rates, and because the survey selected one adult from each household, it is necessary to weight the data to permit generalization to the adult population of China. Also, because the data are from a multistage stratified sample, we use survey estimation procedures to obtain correct standard errors (StataCorp 2007).

The survey gathered extensive information on respondents' life histories, especially family socioeconomic backgrounds. This is a high-quality survey with little missing data. After constructing a missing variable indicator for father's occupational status ${ }^{3}$ and eliminating 31 
cases with missing responses on any of the other variables considered here, the analysis is based on 6,059 cases. Our basic strategy is to estimate a series of OLS regression models predicting years of schooling from the number of siblings plus control variables. To highlight the impact of political shifts and to account for persistent rural-urban and gender differences, we estimate separate models for cohorts corresponding to each of the four periods and, within each period, for rural and urban residents as well as for males and females.

\section{VARIABLES}

The dependent variable is the years of completed schooling, ranging from 0 to $18 .{ }^{4} \mathrm{~A}$ potential problem with this specification of educational attainment is that some respondents could still be in school. However, this was the case for less than 1 percent of the sample. A more serious problem is that about 16 percent of our sample never attended school, and an additional 20 percent left school before age 14. For these respondents, the number of siblings at age 14 (see below) clearly is an imperfect measure of the level of "resource dilution" when their families were making schooling decisions. There is no help for this because we have no other measure of sibship size. Given the relatively close spacing of children, though, we think our measure is a reasonably good proxy for the number of children present when educational decisions were made. We also believe our design is superior to those that predict current school enrollment from the current number of children in a household (e.g., Anh et al. 1998; Patrinos and Psacharopoulos 2004).

Our strategy has several additional advantages. Completed education is of essential interest in educational stratification research. Measures such as children's current educational status may obscure differences between leaving school permanently and short-term interruptions or delays in schooling for reasons that may not affect an individual's ultimate attainment. Additionally, completed education is the preferred variable for examining the role of state policies — we care about the impact of policy on completed education.

The key independent variable is sibship size. We use the total number of siblings at age 14 as an indicator, ranging from 0 to 14 . We truncate it at seven to reduce the leverage of the small number of respondents with a very large sibsize (less than 1 percent of our sample reports eight or more siblings). The sibship size variable is treated as both continuous and discrete in the analysis.

We code gender as a dichotomous variable. To determine gender differences in the sibship size effect, it would be optimal to have information on the gender configuration of a respondent's siblings. For example, girls with many brothers may fare worse than girls with many sisters because of norms and family strategies favoring sons over daughters. Because we do not have such information, all we can do is estimate effects of sibship size separately for girls and boys.

Urban (versus rural) residential status is defined by formal registration status at age 14 . Since 1955, China has had an internal registration (hukou) system, in which each person is assigned to either agricultural or nonagricultural status, with very different rights and privileges (Chan 1994; Wang, Zuo, and Ruan 2002; Wu and Treiman 2004). Registration status is better than actual residence as an indicator of educational opportunities because rural hukou holders living in cities 
were not permitted to attend urban schools. About 20 percent of the sample reached age 14 before the hukou system was established. These people are coded as rural or urban on the basis of their actual residence at age 14 .

We also control for parental education, which is known to be an important determinant of both family size (Axinn and Barber 2001; Cleland and Rodriguez 1988) and offspring's education (Ganzeboom and Treiman 1993; Shavit and Blossfeld 1993; Treiman and Yip 1989), although some recent studies suggest weak or nonexistent effects after controlling for unobserved heterogeneity (Behrman and Rosenzweig 2002; Black et al. 2005b). We define parental education as the years of school completed by the parent who achieved the most schooling. For the handful of cases that had information available for only one parent, we used that information.

For the same reasons, we include father's occupational status (ISEI) ${ }^{5}$ when a respondent was age 14 as another aspect of family socioeconomic background. This information is missing from over 10 percent of the data $(\mathrm{N}=731)$. It is not missing at random; rather, poorly educated people are less likely to know about their parental characteristics. We thus include a dichotomous variable, scored 1 if father's occupation was missing and 0 otherwise, and assign the mean ISEI score to all cases with missing information. We are not able to control for family income or wealth when a respondent was age 14 due to the lack of such information. Parental education and occupational status, however, taken together, serve as a partial control for family economic status.

We divide the sample into four cohorts corresponding to the four periods defined earlier. Studying the effect of historical events on educational attainment using cross-sectional data is difficult because it is unclear where in the educational process the impact is greatest, and an individual's educational process may overlap different historical events. In the present study, we use age 7-the modal school entry age in contemporary China ( $\mathrm{Li}$ and Luo 2004) —as the age at which an individual's education tends to be most affected. Parental decisions affecting children's educational outcomes may depend most powerfully on policies in place during their children's earliest school years because some decisions, once made, cannot be undone. Also, because a parent's influence tends to decline over successive schooling decisions due to individual selectivity (Mare 1981), policies affecting early selection are likely to have the greatest impact. In addition, primary education was far from universal in China (Tsang 2000). In our data, the percentages of children who never attended school for the four cohorts are, respectively, 42, 21, 8 , and $6{ }^{6}$ Because of the substantial variation in early educational attainment, including whether children ever attended school at all, state policies probably had a substantial impact even (or especially) at this level.

We define the four cohorts on the basis of the year respondents turned 7 years old: the precommunist cohort includes those who turned age 7 before or during 1949; the early communist-era cohort includes those who turned age 7 between 1950 and 1965; the Cultural Revolution cohort includes those who turned age 7 between 1966 and 1976; and the economic reform cohort includes those who turned age 7 between 1977 and 1983. Because our choice of dividing points is necessarily somewhat arbitrary, we conducted sensitivity tests by comparing results obtained from different choices of cutting points. Our results are robust to alternative cutting points, especially those based on years close to the school beginning age. 


\section{RESULTS}

\section{DESCRIPTIVE STATISTICS}

Appendix Tables A1 and A2 present descriptive statistics for each cohort as a whole, for cohorts subdivided by residential status, and for cohorts subdivided by gender. The general trends are as expected. We see that the average sibset size declined from almost five children (the number of siblings plus one) in the second cohort to about 3.7 children in the fourth cohort. The decline is particularly sharp for the most recent cohort influenced by the birth control policies. ${ }^{7}$ The relatively high fertility even for the youngest cohort reflects the fact that the one-child policy was not implemented until after 1976, the birth year of our youngest respondents. Meanwhile, the average years of schooling increased from 3.9 before the transition to communism to 8.2 during the economic reform period.

The results largely reflect changes in governmental educational policies. During the precommunist period, the average level of education was very low, with a relatively large dispersion around the mean. After Liberation, the mean years of schooling increased while dispersion decreased. Notably, the greatest change was between the second and third periods, as would be expected given the competitive policies implemented during the second period and the great emphasis on equality during the Cultural Revolution period. Educational outcomes in the economic reform period are not very different from those in the third period, presumably because of offsetting trends: a renewed competitive agenda but also increased opportunity costs associated with the Household Responsibility System.

Table A1 also shows rural-urban disparities period-by-period. The first two periods show essentially no urban-rural difference in the average number of siblings, but the last two periods show a substantial reduction in sibset size for the urban-origin population. Rural-urban differences in educational attainment were strong and consistent across cohorts. The average level of schooling increased monotonically period-by-period in urban areas but remained the same between the third and fourth periods in rural areas. Consistent with the competitive thrust of the second period and the egalitarian thrust of the third period, the average years of schooling increased somewhat more substantially for those of rural origin than for those of urban origin.

Several gender comparisons in Table A1 are of interest. First, policy effects are difficult to discern because they are swamped by the secular trend toward increasing educational equality between males and females. Although males achieved more education in every period, the gender gap systematically declined over time. Second, for males, the level of education declined in the fourth cohort compared with the third. This, too, probably reflects the increased opportunity costs of education during the reform period. Third, in all four periods the number of siblings is slightly greater for females, which is consistent with the claim that when Chinese parents have daughters, they sometimes try again for a son.

As Table A2 shows, even the most recent cohort has substantial variability in family size. Clearly, the fertility control policies implemented in the 1970s had little impact on this cohort, probably because these policies came into full force only late in the decade. This point is 
important because it makes clear that our results likely are not driven by the extreme behavior of a small number of large families.

\section{OVERALl EFFECT}

We first regress years of schooling on sibship size alone. It turns out that the gross cost of each additional sibling in China is about one-fifth of a year of education $(\beta=-.18)$. We observe a significant but smaller cost $(\beta=-.08 ; p=.023$ ) even when controlling for other background variables. We have claimed that the cost of additional siblings is due to the dilution of resources. We are able to make one explicit test, following Downey (1995), by studying the impact of sibset size on the availability of a particular resource: whether respondents had their own study desks at age 14 (via logistic regression and adjusting for other control variables). The logit associated with sibship size $(\beta=-.110 ; p=.004)$ indicates that each additional sibling reduced the odds that a respondent had a study desk by about 10 percent. We suspect that the availability of other resources, both material and intellectual, would be similarly affected by sibsize, but we are unable to make any additional tests.

Next, we extend the overall model by including: (1) interactions between the period dummies and each of the other independent variables; (2) three-way interactions between the period dummies, gender, and each of the other variables; and (3) three-way interactions between the period dummies, registration status, and each of the other variables. ${ }^{8}$ All three models fit significantly better than the overall model $(p<.001)$, and in each model, all the interactions involving sibship size are at least marginally significant. ${ }^{9}$ We conclude that the effect of sibship size varies by period, residential status, and gender, as expected from our theoretical discussion. We therefore estimate separate models in the remainder of the article.

\section{Sibship Size Effects by Period}

Table 1 provides evidence consistent with Hypotheses 1 and $3 .^{10}$ In the second and fourth periods, there are substantial negative effects of sibship size, with each additional sibling costing nearly a fifth of a year of schooling, an effect comparable in size to that observed in developed nations. By contrast, there is no effect of sibship size in the first or third periods. Formal statistical tests confirm that the observed differences in the effects of sibship size are significant $(p<.000$ for the contrast of Periods 1 and 3 versus Periods 2 and 4, and $p<.002$ for the contrast of Period 3 versus Periods 2 and 4).

\section{$<$ TABLE $1>$}

We also estimated parallel models treating sibship size as a set of discrete variables. The results are consistent with those from the continuous specification and thus are not shown here: in the second and fourth periods, the coefficients are increasingly negative in a nearly monotonic way, whereas in the other two periods, the coefficients show no clear pattern.

\section{Sibship Size Effects by Period and Rural/Urban Residential Status}


To test Hypotheses 2.2 and 2.3, we estimate separate models within each period for individuals with rural and urban registration at age 14 (Table 2). Our results show the complex interaction between period and residential status posited earlier.

\section{$<$ TABLE 2>}

In the first period, we expected no differences in sibship size effects (Hypothesis 3). No urbanrural difference should thus exist, and none was found $(p<.983)$. In the second period, sharp urban-rural differences exist: as expected, sibship size hardly mattered for those from urban origins, while it was detrimental for those from rural origins $(p<.06)$. In the third (Cultural Revolution) period, the rural-urban differential effect is reversed, again as expected. No sibship size effect exists for rural children, but there is a substantial negative effect $(-.16)$ for urban children. This contrast, though, is not statistically significant.

The results for the fourth (economic reform) period are consistent with Hypothesis 2.3. As described earlier, this period is characterized by competitive policies, which should lead to a strong sibship size effect. Indeed, we observe just that in urban areas: the cost of each additional child is about a half year of schooling, a very strong effect. The large effect may result in part from intensified birth control policies, particularly in urban areas (Croll, Davin, and Kane 1985; Hsu 1985). As fertility declined, the remaining large families in urban areas may have become increasingly disadvantaged due to policies that encouraged low fertility by compensating small families and penalizing large families. The unusually large effect also may reflect, in part, endogenous quality-quantity calculations made by parents. Given the very large size of the effect, though, it is unlikely that endogenous tradeoffs are entirely responsible.

In rural areas, the sibship size effect, although negative, is small and not statistically significant. This is as expected. Earlier, we hypothesized that in rural areas, the reduction in educational opportunities due to fiscal decentralization and increased competition may have been offset by the introduction of the Household Responsibility System, which increased the opportunity costs of children's education for small rural families. For families engaged in agriculture or a family business, sibship size could actually have had a positive effect on children's education. A partial test of this claim is possible by modeling educational attainment separately for those from rural origins whose fathers were engaged in agriculture or small businesses when the respondent was age 14 and those whose fathers had other occupations. As shown in Table 3, for those whose fathers were not engaged in agriculture or small businesses, there is a substantial negative effect of sibship size (although the effect is only marginally significant due to the small sample size). By contrast, among those whose families were engaged in family enterprises, the sibship size effect does not become positive, but it essentially disappears.

\section{$<$ TABLE 3 $>$}

An explicit test confirms our hypothesized contrast for the rural population of Periods 2 and 4 (competitive) versus Periods 1 and 3 (egalitarian) $(p<.000)$. Such a test is not appropriate for the urban population because we hypothesized a more complex pattern of variation across periods.

\section{SibShip Size by PERIOd ANd GeNDER}


Table 4 shows results pertinent to Hypothesis 2.1. As expected, there is no sibship size effect for males in any period, but for females there is a strong negative effect of sibship size in the two periods characterized by a competitive educational agenda. The sharp gender contrast is consistent with our claim that during periods in which educational competition is strong, girls suffer when family resources are diluted by the presence of many children. The absence of a sibship size effect for males even during competitive periods is consistent with the claim that whatever their circumstances, families try to invest in the education of their sons.

\section{$<$ TABLE 4>}

Our hypothesized contrasts between periods are confirmed by explicit tests: as expected, there is no significant difference for males between competitive periods ( 2 and 4$)$ and egalitarian periods ( 1 and 3 ) in the size of the sibship size effect $(p<.274)$. For females, though, the same contrast is highly significant $(p<.000)$. Differences between males and females are significant in Period 2 $(p<.001)$ but not significant in Periods 1 and 3, all as expected. There is, however, one inconsistent result: in Period 4, the gender difference is not significant $(p<.257)$ even though the coefficient for females is more than twice that for males. This may reflect the relatively small number of respondents in this period.

\section{SUMMARY AND DISCUSSION}

Because of its distinctive history, China presents an unusual opportunity for students of social stratification to explore the impact of government institutions in shaping the educational stratification process. In contrast to developed nations, where the detrimental effect of additional siblings appears to be universal, sibship size effects have varied over time in China in response to vicissitudes in state policy, which alternately promoted educational equality and educational competition. These policies played out in complex ways, affecting males and females and those from urban and rural origins in different ways at different times.

Although somewhat complex in their detail, the results presented here can be summarized quite simply: when schooling opportunities were limited and expensive, children in large families, especially girls, obtained less schooling; when schooling expanded and became relatively less expensive, the detrimental effect of having many siblings disappeared. When competition for schooling is pronounced, family resources - both material and cognitive-become more important, and a larger sibsize results in the dilution of resources available to any given child.

Because of data limitations, our empirical analysis for the most part does not involve direct tests of the presence of resources within families nor of the degree of educational competition. Instead, it proceeds indirectly through comparisons of sibship size effects across four historical periods (precommunist, early communist, Cultural Revolution, and economic reform) and comparisons of effects for males and females and for those from urban and rural origins within each period. We argue that the four periods were characterized by quite different educational policies, succinctly summarized as "egalitarian" and "competitive." 
We find that sibship size had little impact on the education of males in any period due to strong son preferences, which prevail even today in China. During competitive periods, however, large sibship sizes tended to exacerbate the disadvantages already faced by girls. When the state enforced an egalitarian agenda during the Cultural Revolution, though, the disadvantage for girls with many siblings disappeared.

Rural-urban differences in the sibship size effect are more complex. During the precommunist period, sibship size mattered little for anyone because of the extreme limitation in educational opportunities. In the early communist period, when the urban educational system expanded but rural areas were subject to harsh conditions, sibship size had little impact on urban children, while it had a large influence on rural children. During the Cultural Revolution, however, the impact was reversed, with a pronounced sibship size effect in urban areas but not in rural areas.

The economic reform period is particularly complex, with several offsetting pressures. In urban areas, fertility control policies that subsidized families with few children and fined families with many children exacerbated disparities in educational resources between small and large families. The result was an unusually large negative sibship size effect. In rural areas, however, the fertility control policies were not enforced very strongly. Moreover, the effect of increased educational competition was offset by the Household Responsibility System (HRS), which created opportunity costs for families with few children because children were needed to help in the fields. As a result, we observe small and statistically nonsignificant sibship size effects for children of rural origins.

Due to the lack of suitable data, we cannot control for the possibility of endogeneity - that parents decide to limit fertility to maximize children's education. Our analysis suggests, however, that endogeneity is not likely to seriously contaminate our results. Endogenous qualityquantity calculations must have been relatively uncommon in China until the fourth period given the high fertility levels. State policy during the early communist period was strongly pro-natalist due to Mao's advocacy of "mass production," which greatly enhanced the value of and the need for labor, and thus the value of and the demand for children. This campaign was especially strong during the Great Leap Forward Period from 1958 to 1960 (Peng 1987). As Appendix Table A2 shows, fertility was quite high during this period. Although it is possible that some families made endogenous fertility decisions, it must have been uncommon given the extremely strong ideological fever commonly observed in many social arenas during this period. In the Cultural Revolution period, endogenous quality-quantity tradeoffs are beside the point because we observe no sibship size effect. This leaves the economic reform period, in which endogenous quality-quantity tradeoffs could help to account for the extremely high sibship size effect in the urban population. For the rural population, by contrast, the HRS created an incentive for parents to have more children to have more hands in the fields. We have suggested that families with many children kept some of them in school as a risk diversification strategy. None of this is consistent, however, with a decision to limit fertility to promote educational chances.

We conclude that in China, individual life chances under state socialism are extremely sensitive to political processes. By explicitly taking into account state policies, this research contributes to our understanding of the mediating role of government policies in altering opportunity structures in developing societies. The evidence from China clearly illustrates how forces external to the 
family — specifically, policies that affect the availability and cost of schooling — affect internal family dynamics, exacerbating or minimizing the role of sibship size as a determinant of educational outcomes.

The evidence presented in this article suggests that governmental equalizing policies have the potential to eliminate the educational disadvantages faced by children with many siblings, particularly rural children and girls, ultimately reducing educational, gender, and place stratification. Our study, focusing on variations over time within a society, reaches conclusions similar to those of two cross-national studies that show the mediating role of welfare policies (Park 2005; Xu 2003). Our findings should hearten educational policymakers because promoting equalizing policies is far more tractable than eliminating poverty. For comparativists, these results suggest that government policies in developing societies can play crucial roles in altering educational resources available to individual children and in allocating these resources equally for boys and girls and for rural and urban children. We hope our work inspires similar studies of other societies. 


\section{REFERENCES}

Anastasi, Anne. 1956. “Intelligence and Family Size.” Psychological Bulletin 53:187-209.

Anh, Truong S., John Knodel, David Lam, and Jed Friedman. 1998. "Family Size and Children's Education in Vietnam." Demography 35:57-70.

Axinn, William G. and Jennifer S. Barber. 2001. "Mass Education and Fertility Transition." American Sociological Review 66:481-505.

Bakeman, Roger and Josephine V. Brown. 1980. "Early Interaction: Consequences for Social and Mental Development at Three Years." Child Development 51:437-47.

Banister, Judith. 1987. China's Changing Population. Stanford, CA: Stanford University Press.

Banister, Judith and Kenneth Hill. 2004. "Mortality in China 1964-2000.” Population Studies 58:55-75.

Bauer, John, Wang Feng, Nancy E. Riley, and Xiaohua Zhao. 1992. "Gender Inequality in Urban China: Education and Employment.” Modern China 18:333-70.

Baydar, Nazli, Patricia Hyle, and Jeanne Brooks-Gunn. 1997. "A Longitudinal Study of the Effects of the Birth of a Sibling during Preschool and Early Grade School Years." Journal of Marriage and the Family 59:957-65.

Behrman, Jere R., Robert Pollak, and Paul Taubman. 1989. "Family Resources, Family Size, and Access to Financing for College Education.” Journal of Political Economy 92:398-419.

Behrman, Jere R. and Mark R. Rosenzweig. 2002. 'Does Increasing Women's Schooling Raise the Schooling of the Next Generation?" American Economic Review 91:323-34.

Belmont, Lillian and Francis A. Marolla. 1973. "Birth Order, Family Size, and Intelligence." Science 182:1096-1101.

Bernstein, Thomas P. 1977. Up to the Mountains and Down to the Villages: The Transfer of Youth from Urban to Rural China. New Haven, CT: Yale University Press.

Black, Sandra E., Paul J. Devereux, and Kjell G. Salvanes. 2005a. "The More the Merrier? The Effect of Family Composition on Children's Education." The Quarterly Journal of Economics, 120:669-700.

—. 2005b. "Why the Apple Doesn't Fall Far: Understanding Intergenerational Transmission of Human Capital." American Economic Review 95:437-49.

Blake, Judith. 1981. "Family Size and the Quality of Children.” Demography 18:421-42. 1989. Family Size and Achievement. Berkeley, CA: University of California Press. 
Blau, Peter M. and Otis Dudley Duncan. 1967. The American Occupational Structure. New York: Wiley.

Breland, Hunter M. 1974. "Birth Order, Family Configuration, and Verbal Achievement." Child Development 45:1011-19.

Buchmann, Claudia and Emily Hannum. 2001. "Education and Stratification in Developing Countries: A Review of Theories and Research.” Annual Review of Sociology 27:77-102.

Chan, Kam Wing. 1994. Cities with Invisible Walls. Hong Kong: Oxford University Press.

Chu, C.Y. Cyrus, Yu Xie, and Ruoh-rong Yu. 2007. "Effects of Sibship Structure Revisited: Evidence from Intrafamily Resource Transfer in Taiwan.” Sociology of Education 80:91-113.

Chu, Cyrus, R. R. Yu, and Ruey S. Tsay. 2004. "A SSAD Model of Family Resource Allocation among Siblings: Competition, Forbearance, and Support." Paper presented at a meeting of The Research Committee on Social Stratification and Mobility (RC28), Neuchatel, Switzerland, May.

Clarke-Stewart, A. 1988. "Parents' Effects on Children's Development: A Decade of Progress?" Journal of Applied Developmental Psychology 9:41-84.

Cleland, John and German Rodriguez. 1988. "The Effect of Parental Education on Marital Fertility in Developing Countries." Population Studies 42:419-42.

Conley, Dalton and Rebecca Glauber. 2006. "Parental Educational Investment and Children's Academic Risk: Estimates of the Impact of Sibship Size and Birth Order from Exogenous Variation in Fertility." Journal of Human Resources 41:722-37.

Croll, Elizabeth, Delia Davin, and Penny Kane. 1985. China's One-Child Family Policy. New York: St. Martin's Press.

Deng, Zhong and Donald J. Treiman. 1997. "The Impact of the Cultural Revolution on Trends in Educational Attainment in the People's Republic of China." American Journal of Sociology 97:391-428.

Downey, Douglas B. 1995. "When Bigger Is Not Better: Family Size, Parental Resources, and Children's Educational Performance.” American Sociological Review 60:746-61.

Downey, Douglas B., Brian Powell, Lala C. Steelman, and Shana Pribesh. 1999. "Much Ado about Siblings: Change Models, Sibship Size, and Intellectual Development." American Sociological Review 64:193-98.

Duncan, Otis Dudley. 1961. "A Socioeconomic Index for All Occupations.” Pp. 109-39 in Occupations and Social Status, edited by A J. Reiss Jr. New York: Free Press of Glencoe. 
Featherman, David L. and Robert M. Hauser. 1978. Opportunity and Change. New York: Academic Press.

Ganzeboom, Harry B. G., Paul M. De Graaf, and Donald J. Treiman. 1992. “A Standard International Socio-Economic Index of Occupational Status." Social Science Research 21:1-56.

Ganzeboom, Harry B. G. and Donald J. Treiman. 1993. "Preliminary Results on Educational Expansion and Educational Achievement in Comparative Perspective." Pp. 467-506 in Solidarity of Generations: Demographic, Economic and Social Change, and Its Consequences, edited by H. A. Becker and P. L. J. Hermkens. Amsterdam: Thesis Publishers.

Gomes, Melba. 1984. "Family Size and Educational Attainment in Kenya." Population and Development Review 10:647-60.

Gottfried, A. W. and A. E. Gottfried. 1984. Home Environment and Early Cognitive Development. New York: Academic Press.

Guo, Guang and Leah VanWey. 1999. "Sibship Size and Intellectual Development: Is the Relationship Causal?”'American Sociological Review 64:169-87.

Han, Dongping. 2001. "Impact of the Cultural Revolution on Rural Education and Economic Development: The Case of Jimo County." Modern China 27:59-90.

Hannum, Emily. 1999. "Political Change and the Urban-Rural Gap in Basic Education in China, 1949-1990." Comparative Education Review 43:193-211.

Hannum, Emily and Yu Xie. 1994. "Trends in Educational Gender Inequality in China: 19491985." Research in Social Stratification and Mobility 13:73-98.

Hauser, Robert M. and William H. Sewell. 1985. "Birth Order and Educational Attainment in Full Sibships.” American Educational Research Journal 22:1-23.

Hermalin, Albert I., Judith Seltzer, and Ching-Hsiang Lin. 1982. "Transitions in the Effect of Family Size on Female Education and Educational Attainment: The Case of Taiwan."

Comparative Educational Review 26:245-70.

Hsu, Mei-Ling. 1985. "Growth and Control of Population in China: The Urban-Rural Contrast." Annals of the Association of American Geographers 75:241-57.

Kessler, Daniel. 1991. "Birth Order, Family Size, and Achievement: Family Structure and Wage Determination." Journal of Labor Economics 9:413-26.

Knight, John and Li Shi. 1996. "Educational Attainment and the Rural-Urban Divide in China." Oxford Bulletin of Economics and Statistics 58:83-117. 
Kuo, Hsiang-Hui D. and Robert M. Hauser. 1997. "How Does Size of Sibship Matter? Family Configuration and Family Effects on Educational Attainment." Social Science Research 26:6994.

Lavely, William and Ronald Freedman. 1990. "The Origins of the Chinese Fertility Decline." Demography 27:357-67.

Lavely, William, Zhenyu Xiao, Bohua Li, and Ronald Freedman. 1990. "The Rise in Female Education in China: National and Regional Patterns." China Quarterly 121:61-93.

Li, Haizheng and Yi Luo. 2004. "Reporting Errors, Ability Heterogeneity, and Returns to Schooling in China." Pacific Economic Review 9:191-207.

Lloyd, Cynthia. 1994. "Investing in the Next Generation: The Implications of High Fertility at the Level of the Family." Pp. 181-202 in Population and Development: Old Debates and New Conclusions, edited by R. Cassen. New Brunswick, NJ: Transaction Publishers.

Lu, Yao. 2005. "Sibship Size, Family Organization, and Children's Education in South Africa: Black-White Variations." Population Working Paper PWP-CCPR-2005-045. Los Angeles, CA: UCLA, California Center for Population Research.

Maralani, Vida. 2004. "The Changing Relationship between Family Size and Educational Attainment in Indonesia." Population Working Paper PWP-CCPR-2004-017. Los Angeles, CA: UCLA, California Center for Population Research.

Mare, Robert D. 1981. "Change and Stability in Educational Stratification." American Sociological Review 46:72-87.

Mare, Robert D. and M. Chen. 1986. "Further Evidence on Sibship Size and Educational Stratification." American Sociological Review 51:403-12.

Marjoribanks, K., H. Walberg, and M. Bargen. 1975. "Mental Abilities: Sibling Constellation and Social Class Correlates." British Journal of Social and Clinical Psychology 14:109-16.

Ministry of Education. 1981. Education in China. Beijing: Education in China Group.

Mueller, Eva. 1984. "Income, Aspirations, and Fertility in Rural Areas of Less Developed Countries." Pp. 121-50 in Rural Development and Human Fertility, edited by W. A. Schutjer and C. S. Stokes. New York: Macmillan.

Nisbet, J. D. and N. J. Entwistle. 1967. "Intelligence and Family Size, 1949-1965." British Journal of Educational Psychology 37:188-93.

Parish, William L. and Robert J. Willis. 1993. "Daughters, Education, and Family Budgets: Taiwan Experiences." Journal of Human Resources 28:863-98. 
Park, Hyunjoon. 2005. "Public Policy and the Effect of Sibship Size on Educational Achievement: A Comparative Study of 20 Countries." Paper presented at the annual meeting of the Population Association of America, Philadelphia, PA, March.

Patrinos, Harry A. and George Psacharopoulos. 2004. "Family Size, Schooling and Child Labor in Peru: An Empirical Analysis.” Journal of Population Economics 10:387-405.

Peng, Xizhe. 1987. "Demographic Consequences of The Great Leap Forward in China's Provinces.” Population and Development Review 13:639-70.

Peng, Xizhe and Zhigang Guo, eds. 2000. The Changing Population of China. Oxford, UK: Blackwell.

Philips, Meredith. 1999. "Sibship Size and Academic Achievement: What We Now Know and What We Still Need to Know.” American Sociological Review 24:1-24.

Pong, Suet-Ling. 1997. "Sibship Size and Educational Attainment in Peninsular Malaysia: Do Policies Matter?” Sociological Perspectives 40:227-42.

Post, David and Suet-Ling Pong. 1998. "The Waning Effect of Sibship Composition on School Attainment in Hong Kong." Comparative Education Review 42:99-117.

Poston, Dudley L. 2002. "Son Preference and Fertility in China." Journal of Biosocial Science $34: 333-47$.

Powell, Brian, Regina Werum, and Lala Carr Steelman. 2004. "Macro Causes, Micro Effects: Linking Public Policy, Family Structure, and Educational Outcomes." Pp. 111-44 in After the Bell: Family Background, Public Policy, and Educational Success, edited by D. Conley and K. Albright. New York: Routledge.

Rong, Xuelang and Tianjian Shi. 2001. "Inequality in Chinese Education." Journal of Contemporary China 10:107-24.

Roos, Patricia A. and Mary L. Gatta. 1999. "The Gender Gap in Earnings: Trends, Explanations, and Prospects." Pp. 95-123 in Handbook of Gender and Work, edited by G. N. Powell. Thousand Oaks, CA: Sage.

Rosenzweig, Mark R. and Kenneth I. Wolpin. 1980. "Testing the Quantity-Quality Fertility Model: The Use of Twins as a Natural Experiment.” Econometrica 48:227-40.

Shavit, Yossi and Hans-Peter Blossfeld, eds. 1993. Persistent Inequality: Changing Educational Attainment in Thirteen Countries. Boulder, CO: Westview Press.

Shavit, Yossi and Jennifer L. Pierce. 1991. "Sibship Size and Educational Attainment in Nuclear and Extended Families: Arabs and Jews in Israel." American Sociological Review 56:321-30. 
StataCorp. 2007. Stata Survey Data Reference Manual: Release 10.0. College Station, TX: Stata Press.

Steelman, Lala C. and Brian Powell. 1985. "The Academic and Social Consequences of Birth Order: Real, Artifactual or Both?” Journal of Marriage and the Family 47:117-24.

Steelman, Lala C., Brian Powell, Regina Werum, and Scott Carter. 2002. "Reconsidering the Effects of Sibling Configuration: Recent Advances and Challenges." Annual Review of Sociology 28:243-69.

Sudha, Shreeniwas. 1997. "Family Size, Sex Composition and Children's Education: Ethnic Differentials over Development in Peninsular Malaysia." Population Studies 51:139-51.

Summerfield, Gale. 1994. "Economic Reform and the Employment of Chinese Women." Journal of Economic Issues 28:715-32.

Treiman, Donald J. 1998. Life Histories and Social Change in Contemporary China: Provisional Codebook. Los Angeles, CA: UCLA Institute for Social Science Research.

- 2007. "Growth and Determinants of Literacy in China." Pp. 135-53 in Education and Reform in China, edited by E. Hannum and A. Park. Oxford, UK: Routledge.

Treiman, Donald J. and Patricia A. Roos. 1983. "Sex and Earnings in Industrial Society: A Nine Nation Comparison." American Journal of Sociology 89:612-50.

Treiman, Donald J. and Andrew G. Walder. 1996. Life Histories and Social Change in Contemporary China. Distributed by the UCLA Social Science Data Archive (http://www.sscnet.ucla.edu/issr/da/).

Treiman, Donald J. and Kam-bor Yip. 1989. "Educational and Occupational Attainment in 21 Countries." Pp. 373-94 in Cross-National Research in Sociology (ASA Presidential Series), edited by M. L. Kohn. Beverly Hills, CA: Sage Publications.

Tsang, Mun C. 1996. "Financial Reform of Basic Education in China." Economics of Education Review 15:423-44.

- 2000. "Education and National Development in China since 1949: Oscillating Policies and Enduring Dilemmas." China Review 2000:579-618.

- 2003. "Intergovernmental Grants and the Financing of Compulsory Education in China.” Pp. 267-86 in Providing Adequate Resources to Education, edited by W. Min, Z. Yang, and W. Li. Beijing, China: People's Education Press.

Tsui, Kai-Yuen. 1997. "Economic Reform and Attainment in Basic Education in China." The China Quarterly 149:104-27. 
Unger, Jonathan. 1982. Education under Mao: Class and Competition in Canton Schools, 19601980. New York: Columbia University Press.

Wang, Feng, Xuejin Zuo, and Danching Ruan. 2002. "Rural Migrants in Shanghai: Living Under the Shadow of Socialism.” International Migration Review 36:520-45.

Wu, Xiaogang and Donald J. Treiman. 2004. "The Household Registration System and Social Stratification in China: 1955-1996." Demography 41:363-84.

- 2007. "Inequality and Equality under Chinese Socialism: The Hukou System and Intergenerational Occupational Mobility." American Journal of Sociology 113: 415-45.

$\mathrm{Xu}$, Jun. 2003. "The Effects of Nation States on the Association between Family Structure and Educational Performance in 20 Industrialized Nations." Paper presented at the American Sociological Association Annual Meeting, Atlanta, GA.

Yan, Yunxiang. 2003. Private Life under Socialism: Love, Intimacy, and Family Change in a Chinese Village, 1949-1999. Stanford, CA: Stanford University Press.

Zhang, Junsen. 1990. "Socioeconomic Determinants of Fertility in China: A Microeconometric Analysis.” Journal of Population Economics 3:105-23.

Zhou, Xueguang, Phyllis Moen, and Nancy B. Tuma. 1998. "Educational Stratification in Urban China: 1949-94." Sociology of Education 71:199-222.

Zimmer, Zachary and Julia Kwong. 2004. "Socioeconomic Status and Health among Older Adults in Rural and Urban China." Journal of Aging and Health 16:44-70. 


\section{TABLES}

Table 1. Coefficients from OLS Regressions of Years of Schooling on Sibship Size and Control Variables, Separately by Period

\begin{tabular}{lcccc}
\hline \hline Independent & $\begin{array}{c}\text { Period } 1 \\
\text { (Pre- } \\
\text { Variables }\end{array}$ & $\begin{array}{c}\text { Period 2 } \\
\text { (Early Years }\end{array}$ & $\begin{array}{c}\text { Period 3 } \\
\text { (Cultural } \\
\text { Revolution) }\end{array}$ & $\begin{array}{c}\text { Period 4 } \\
\text { (Economic } \\
\text { Reform) }\end{array}$ \\
\hline Number of & -.044 & -.164 & -.032 & -.153 \\
Siblings & .443 & .003 & .649 & .039 \\
Male & 2.553 & 2.291 & 1.437 & .590 \\
& .000 & .000 & .000 & .011 \\
Urban & 2.343 & 2.662 & 1.999 & 1.685 \\
& .000 & .000 & .000 & .000 \\
Parental & .386 & .219 & .173 & .232 \\
Schooling & .000 & .000 & .000 & .000 \\
Father's ISEI & .037 & .028 & .021 & .028 \\
& .003 & .001 & .000 & .001 \\
Father's ISEI & -.761 & -1.018 & -.664 & -.167 \\
Missing & .012 & .000 & .119 & .693 \\
Constant & .829 & 3.837 & 5.760 & 5.824 \\
& .015 & .000 & .000 & .000 \\
$\mathrm{R}^{2}$ & .275 & .253 & .214 & .312 \\
Unweighted N & 1,260 & 2,240 & 1,766 & 793 \\
\hline
\end{tabular}

Notes: ISEI $=$ International Socioeconomic Index of Occupations. $p$ values (two-tailed tests) are in italics. 
Table 2. Coefficients from OLS Regressions of Years of Schooling on Sibship Size and Control Variables, Separately by Period and Residential Status at Age 14

\begin{tabular}{|c|c|c|c|c|c|c|c|c|}
\hline \multirow{2}{*}{$\begin{array}{l}\text { Independent } \\
\text { Variables }\end{array}$} & $\begin{array}{r}\text { Peri } \\
(\mathrm{Pr} \\
\text { Libera }\end{array}$ & $\begin{array}{l}\text { od } 1 \\
\text { e- } \\
\text { tion) }\end{array}$ & $\begin{array}{r}\text { Per } \\
\text { (Early } \\
\text { at } \\
\text { Libe }\end{array}$ & $\begin{array}{l}\mathrm{d} 2 \\
\text { Years } \\
\text { er } \\
\text { tion) }\end{array}$ & $\begin{array}{r}\mathrm{Pe} \\
(\mathrm{Cu} \\
\mathrm{Revo} \\
\end{array}$ & $\begin{array}{l}\text { od } 3 \\
\text { ural } \\
\text { ation) }\end{array}$ & \multicolumn{2}{|c|}{$\begin{array}{c}\text { Period } 4 \\
\text { (Economic } \\
\text { Reform) }\end{array}$} \\
\hline & Urban & Rural & Urban & Rural & Urban & Rural & Urban & Rural \\
\hline Number of & .027 & -.052 & -.011 & -.199 & -.163 & -.010 & -.507 & -.090 \\
\hline Siblings & .841 & .414 & .889 & .001 & .066 & .902 & .000 & .270 \\
\hline Male & 1.697 & 2.770 & 1.001 & 2.542 & .062 & 1.752 & -.001 & .765 \\
\hline & .003 & .000 & .001 & .000 & .811 & .000 & .999 & .004 \\
\hline Parental & .458 & .329 & .185 & .233 & .133 & .181 & .144 & .258 \\
\hline Schooling & .000 & .000 & .000 & .000 & .000 & .000 & .005 & .000 \\
\hline Father's ISEI & .033 & .045 & .028 & .034 & .024 & .022 & .008 & .037 \\
\hline & .065 & .009 & .006 & .003 & .005 & .002 & .409 & .000 \\
\hline Father's ISEI & -.096 & - & .267 & - & .140 & -.935 & -.836 & -.217 \\
\hline Miss & .866 & $\begin{array}{r}1.011 \\
.005\end{array}$ & .615 & $\begin{array}{r}1.324 \\
.000\end{array}$ & .686 & .074 & .094 & .662 \\
\hline Constant & $\begin{array}{r}3.352 \\
.000\end{array}$ & $\begin{array}{l}.707 \\
.086\end{array}$ & $\begin{array}{r}6.610 \\
.000\end{array}$ & $\begin{array}{r}3.724 \\
.000\end{array}$ & $\begin{array}{r}8.971 \\
.000\end{array}$ & $\begin{array}{r}5.474 \\
.000\end{array}$ & $\begin{array}{r}10.379 \\
.000\end{array}$ & $\begin{array}{r}5.225 \\
.000\end{array}$ \\
\hline $\mathrm{R}^{2}$ & .200 & .206 & .149 & .169 & .157 & .124 & .228 & .156 \\
\hline $\begin{array}{l}\text { Unweighted } \\
\mathrm{N}\end{array}$ & 388 & 872 & 618 & 1,622 & 488 & 1,278 & 236 & 557 \\
\hline
\end{tabular}

Notes: $\mathrm{ISEI}=$ International Socioeconomic Index of Occupations. $p$ values (two-tailed tests) are in italics. 
Table 3. Coefficients from OLS Regressions of Years of Schooling on Sibship Size and Control Variables, by Father's Occupation at Age 14, Economic Reform Cohort with Rural Status at Age 14

\begin{tabular}{lrc}
\hline $\begin{array}{l}\text { Independent } \\
\text { Variables }\end{array}$ & \multicolumn{1}{c}{$\begin{array}{c}\text { Agriculture or Small } \\
\text { Business (getihu) }\end{array}$} & Other \\
\hline Number of Siblings & -.028 & -.266 \\
& .755 & .144 \\
Male & .730 & .759 \\
& .014 & .080 \\
Parental Schooling & .280 & .202 \\
& .000 & .035 \\
Constant & 5.578 & 7.823 \\
& .000 & .000 \\
$\mathrm{R}^{2}$ & .107 & .114 \\
Unweighted N & 441 & 110 \\
\hline
\end{tabular}

Note: $p$ values (two-tailed tests) are in italics. 
Table 4. Coefficients of OLS Regressions of Years of Schooling on Sibship Size and Control Variables, Separately by Period and Gender

\begin{tabular}{|c|c|c|c|c|c|c|c|c|}
\hline \multirow{2}{*}{$\begin{array}{l}\text { Independent } \\
\text { Variables } \\
\end{array}$} & \multicolumn{2}{|c|}{$\begin{array}{c}\text { Period } 1 \\
\text { (Pre- } \\
\text { Liberation) }\end{array}$} & \multicolumn{2}{|c|}{$\begin{array}{c}\text { Period } 2 \\
\text { (Early } \\
\text { Years after } \\
\text { Liberation) }\end{array}$} & \multicolumn{2}{|c|}{$\begin{array}{c}\text { Period } 3 \\
\text { (Cultural } \\
\text { Revolution) }\end{array}$} & \multicolumn{2}{|c|}{$\begin{array}{c}\text { Period } 4 \\
\text { (Economic } \\
\text { Reform) }\end{array}$} \\
\hline & Male & Female & Male & Female & Male & Female & Male & Female \\
\hline Number of & -.147 & .096 & -.004 & -.324 & .003 & -.066 & -.076 & -.197 \\
\hline Sibl & 121 & .164 & .953 & .000 & .976 & .454 & .409 & .051 \\
\hline \multirow[t]{2}{*}{ Urban } & 1.827 & 2.989 & 2.152 & 3.219 & 1.234 & 2.786 & 1.233 & 2.151 \\
\hline & .001 & .000 & .000 & .000 & .000 & .0 & .0 & .0 \\
\hline Pare & .369 & .419 & .225 & .212 & .186 & .1 & .257 & .218 \\
\hline Schooling & .000 & .000 & .000 & .000 & .000 & .000 & .001 & .000 \\
\hline \multirow[t]{2}{*}{ Father's ISEI } & .045 & .025 & 011 & .043 & .017 & .026 & .030 & .023 \\
\hline & & .11 & .356 & .000 & .038 & & .000 & .096 \\
\hline Fathe & -1.644 & .407 & - & - & - & -.375 & .538 & -.687 \\
\hline Missing & 000 & .255 & $\begin{array}{l}1.013 \\
.003\end{array}$ & $\begin{array}{l}1.004 \\
.006\end{array}$ & $\begin{array}{l}1.078 \\
.050\end{array}$ & .525 & .407 & .294 \\
\hline \multirow[t]{2}{*}{ Constant } & 3.842 & .234 & 6.019 & 4.004 & 7.284 & 5.645 & 6.069 & 6.094 \\
\hline & .000 & .571 & .000 & .000 & .000 & .000 & .000 & .000 \\
\hline $\mathrm{R}^{2}$ & .176 & .280 & .151 & .235 & .159 & .205 & .308 & .316 \\
\hline Unweighted $N$ & 665 & 595 & 1,156 & 1,084 & 855 & 911 & 399 & 394 \\
\hline
\end{tabular}

Notes: ISEI = International Socioeconomic Index of Occupations. Standard errors are in parentheses; $p$ values (two-tailed tests) are in italics. 


\section{FOOTNOTES}

${ }^{1}$ We use Hannum and Xie's (1994) "egalitarian" and "competitive" terminology to distinguish the two competing policies. Although any dichotomization of historical periods will necessarily be something of a simplification, we think this dichotomy captures an important policy contrast central to our analysis.

${ }^{2}$ We conducted exploratory analyses in which we divided the 1950 to 1965 years into two periods: 1950 to 1957 and 1958 to 1965 . The results for the two periods were substantially similar. Thus, in the interest of parsimony and to increase the sample size, we analyze four rather than five periods.

${ }^{3}$ Father's occupation is the only variable in the analysis that has missing data for more than a handful of cases.

${ }^{4}$ Our measure of years of schooling in the data is a simple transformation of a respondent's highest educational level.

${ }^{5}$ Father's occupational status is measured by the International Socioeconomic Index of Occupations (ISEI) (Ganzeboom, De Graaf, and Treiman 1992). This scale behaves in a manner similar to the well-known Duncan (1961) SEI.

${ }^{6}$ Even for the fourth cohort, primary school education was not required. This cohort typically began school between 1977 and 1983, but the Compulsory Education Law was not implemented until 1986.

${ }^{7}$ The somewhat lower average sibset size for the first cohort compared with that for the second cohort probably reflects a combination of differential mortality by SES and the disruption of the war years. Those from large sibsets were likely to be of low SES (Lavely and Freedman 1990; Zhang 1990) and hence were disproportionately likely to have died prior to the survey date (Banister and Hill 2004; Zimmer and Kwong 2004). Also, infant mortality was particularly high during the war years (Banister 1987; Peng and Guo 2000). We conducted sensitivity analyses to assess the impact of differential mortality on the sibship size effect for the first cohort. We tried both random sampling from respondents in this cohort and oversampling respondents with a high SES background (whose parents received at least some middle school education). These analyses yield very similar conclusions to those we report.

${ }^{8}$ Sample size limitations preclude testing four-way interactions.

${ }^{9}$ For the three models, the $p$-values from adjusted Wald tests were, respectively, .12, .05, and .03 .

${ }^{10}$ Table 1 also shows other changes in factors affecting educational attainment that are not directly pertinent to our analysis. First, consistent with Deng and Treiman's (1997) claim that the Cultural Revolution greatly undercut the effect of family socioeconomic status on educational attainment, the effects of parental education and father's ISEI are smallest for the Cultural Revolution cohort. Also, the male advantage in educational attainment systematically decreases 
over time, from about two and one-half years in the first cohort to just over a half year in the fourth cohort. 


\section{ppendix}

Table A1. Means and Percentages by Period, Rural versus Urban Residential Status, and Gender; Chinese Adults $1996(\mathrm{~N}=6,059)$

\begin{tabular}{|c|c|c|c|c|c|c|c|c|c|c|}
\hline & \multicolumn{2}{|c|}{$\begin{array}{c}\text { Period } 1 \\
\text { (Pre- } \\
\text { Liberation) }\end{array}$} & \multicolumn{2}{|c|}{$\begin{array}{c}\text { Period } 2 \\
\text { (Early Years } \\
\text { after Liberation) }\end{array}$} & \multicolumn{2}{|c|}{$\begin{array}{c}\text { Period } 3 \\
\text { (Cultural } \\
\text { Revolution) }\end{array}$} & \multicolumn{2}{|c|}{$\begin{array}{c}\text { Period } 4 \\
\text { (Economic } \\
\text { Reform) }\end{array}$} & \multicolumn{2}{|c|}{ Total } \\
\hline & Mean & $\mathrm{SD}$ & Mean & SD & Mean & SD & Mean & $\mathrm{SD}$ & Mean & $\mathrm{SD}$ \\
\hline \multicolumn{11}{|c|}{ Respondent's Schooling } \\
\hline Total & 3.9 & 4.2 & 5.9 & 4.0 & 8.0 & 3.6 & 8.2 & 3.3 & 6.4 & 4.1 \\
\hline Urban & 6.5 & 4.7 & 9.0 & 3.2 & 10.5 & 2.4 & 11.0 & 2.3 & 9.2 & 3.7 \\
\hline Rural & 3.2 & 3.8 & 5.3 & 3.9 & 7.4 & 3.5 & 7.4 & 3.1 & 5.8 & 4.0 \\
\hline Males & 5.0 & 4.1 & 7.0 & 3.5 & 8.8 & 3.2 & 8.4 & 3.2 & 7.2 & 3.8 \\
\hline Females & 2.5 & 3.8 & 4.7 & 4.1 & 7.2 & 3.8 & 7.9 & 3.4 & 5.5 & 4.3 \\
\hline \multicolumn{11}{|c|}{ Number of Siblings } \\
\hline Total & 3.1 & 1.8 & 3.7 & 1.8 & 3.6 & 1.6 & 2.7 & 1.6 & 3.4 & 1.8 \\
\hline Urban & 3.1 & 1.9 & 3.6 & 1.9 & 3.0 & 1.6 & 2.2 & 1.3 & 3.1 & 1.8 \\
\hline Rural & 3.0 & 1.8 & 3.7 & 1.8 & 3.7 & 1.6 & 2.9 & 1.6 & 3.4 & 1.8 \\
\hline Males & 3.0 & 1.8 & 3.6 & 1.9 & 3.5 & 1.7 & 2.5 & 1.4 & 3.3 & 1.8 \\
\hline Females & 3.1 & 1.8 & 3.7 & 1.8 & 3.7 & 1.6 & 2.9 & 1.7 & 3.5 & 1.8 \\
\hline \multicolumn{11}{|c|}{ Parental Schooing } \\
\hline Total & 1.6 & 2.7 & 2.3 & 3.2 & 4.2 & 4.0 & 5.9 & 4.1 & 3.2 & 3.8 \\
\hline Urban & 2.8 & 3.7 & 4.5 & 4.3 & 7.1 & 4.5 & 9.7 & 3.9 & 5.7 & 4.8 \\
\hline Rural & 1.4 & 2.3 & 1.8 & 2.7 & 3.5 & 3.6 & 5.0 & 3.6 & 2.7 & 3.3 \\
\hline Males & 1.6 & 2.7 & 2.3 & 3.3 & 4.3 & 4.1 & 5.8 & 4.1 & 3.2 & 3.8 \\
\hline Females & 1.7 & 2.7 & 2.2 & 3.1 & 4.0 & 4.0 & 6.1 & 4.1 & 3.2 & 3.8 \\
\hline \multicolumn{11}{|c|}{ Father's ISEI } \\
\hline Total & 23.1 & 12.0 & 23.2 & 13.2 & 26.8 & 17.1 & 26.7 & 17.0 & 24.7 & 14.9 \\
\hline Urban & 31.2 & 15.8 & 36.2 & 17.2 & 43.1 & 17.7 & 47.3 & 16.8 & 38.9 & 17.9 \\
\hline Rural & 21.0 & 9.9 & 20.8 & 10.7 & 23.1 & 14.7 & 21.5 & 12.6 & 21.5 & 12.0 \\
\hline Males & 22.9 & 11.9 & 23.0 & 12.9 & 27.0 & 17.3 & 26.1 & 16.8 & 24.5 & 14.7 \\
\hline Females & 23.3 & 12.2 & 23.5 & 13.6 & 26.5 & 17.0 & 27.4 & 17.3 & 24.9 & 15.1 \\
\hline \multicolumn{11}{|c|}{ Father's ISEI Missing } \\
\hline Total & $23.0 \%$ & & 12.9 & & 4.9 & & 5.3 & & 11.6 & \\
\hline Urban & $24.5 \%$ & & 11.9 & & 6.1 & & 4.3 & & 11.9 & \\
\hline Rural & $22.6 \%$ & & 13.1 & & 4.7 & & 5.6 & & 11.6 & \\
\hline Males & $23.0 \%$ & & 13.3 & & 4.7 & & 4.7 & & 11.8 & \\
\hline Females & $22.9 \%$ & & 12.6 & & 5.2 & & 5.9 & & 11.5 & \\
\hline \multicolumn{11}{|l|}{ Male } \\
\hline Total & $55.0 \%$ & & 50.9 & & 50.1 & & 52.0 & & 51.7 & \\
\hline Urban & $54.5 \%$ & & 50.8 & & 52.4 & & 51.9 & & 52.2 & \\
\hline Rural & $55.2 \%$ & & 50.9 & & 50.0 & & 52.4 & & 51.6 & \\
\hline \multicolumn{11}{|l|}{ Urban } \\
\hline Total & $20.2 \%$ & & 15.9 & & 18.3 & & 20.2 & & 18.1 & \\
\hline Male & $20.0 \%$ & & 15.9 & & 19.1 & & 20.1 & & 18.3 & \\
\hline Female & $20.5 \%$ & & 16.0 & & 17.5 & & 20.3 & & 17.9 & \\
\hline \multicolumn{11}{|c|}{ Unweighted $\mathrm{N}$} \\
\hline Total & 1,260 & & 2,240 & & 1,766 & & 793 & & 6,059 & \\
\hline Urban & 388 & & 618 & & 488 & & 236 & & 1,730 & \\
\hline Rural & 872 & & 1,622 & & 1,278 & & 557 & & 4,329 & \\
\hline Males & 665 & & 1,156 & & 855 & & 399 & & 3,075 & \\
\hline
\end{tabular}


Vote: ISEI = International Socioeconomic Index of Occupations. 